\title{
TG13
}

\section{Evaluating Basin-centered Gas Potential in Southwest Ghawar, Saudi Arabia}

\author{
M.A. Al-Duhailan* (Saudi Aramco) \& M.J. Al-Mahmoud (Saudi Aramco)
}

\section{SUMMARY}

A regional study was conducted to evaluate the potential for a basin-centered gas (BCG) accumulation system in the Silurian-Permian sequence at a basin located southwest of the Ghawar field.

Analyzing the critical interaction between the thermal maturity of the Silurian Qusaiba source rock, the low permeability of the Silurian-Permeain reservoir rocks and their relationship with reservoir pressure and fluid type distribution indicates a high potential for an effective basin-centered gas system. Local breaching of the system's effectivity is reflected by the presence of water on the flanks of the basincentered gas accumulation and around faults located in the center of the basin.

This study uses a newly established evaluation process for generating basin-gas play concepts. The evaluation process focuses on analyzing six critical elements denoted as "BCG System Elements." The BCG System Elements include the thermal maturity of the source rock, proximity to source rock, reservoir quality, abnormality of reservoir pressures, regional fluid distribution, and the effectivity of interactions among these five elements. 